\title{
“QUE SAUDADE DA AMÉLIA...”: UMA ANÁLISE SOBRE A VIOLÊNCIA CONTRA A MULHER NA REGIÁO DO CARIRI CEARENSE E O PROJETO DA CASA ABRIGO
}

"I MISS AMELIA...": AN ANALYSIS OF VIOLENCE AGAINST WOMEN IN THE REGION OF CARIRI, CEARÁ AND THE PROJECT OF THE HOUSE SHELTER

Priscila Ribeiro Jeronimo Diniz

Doutoranda em Ciências das Religióes pela UFPB. Mestre em Sociologia - UFPB. Bacharel em Ciências Sociais pela URCA. Docente na Faculdade Paraíso do Ceará (FAPCE).

Coordenadora do Grupo de Estudos de Gênero, Geração e Direito (FAPCE)

priscilaribeiroj@hotmail.com

Debora Cristyna Ferreira Reis

Acadêmica de Direito e Pesquisadora-discente do Grupo de Estudos em Gênero, Geração e Direito pela Faculdade Paraíso do Ceará - (FAPCE)

debora-cristina1945@hotmail.com

Gustavo Leite Neves da Luz

Acadêmico de Direito e Pesquisador-discente do Grupo de Estudos em Gênero, Geração e Direito pela Faculdade Paraíso do Ceará (FAPCE)

gustavoleiteluz@gmail.com 


\section{INTRODUÇÁO}

As questóes de diferença de gênero que envolvem a violência ${ }^{1}$ de gênero vão muito além do que simples atos de machismo e de violência. Tal assunto é de formaçâo histórica, encontrando-se presente em grande parte das sociedades, tornando leis como a Lei $\mathrm{n}^{\circ}$ 11.340 de 2006 (Lei Maria da Penha) ${ }^{2}$ apenas afirmaçóes de culpa de uma sociedade que náo consegue proteger as mulheres. ${ }^{3}$

Entrega-se por meio de um sistema dualista de divisão de coisas, onde os sexos masculino e feminino se estabelecem como opostos que se enquadram "perfeitamente" convenientes a um sistema de oposiçóes homólogas. Sendo esquemas suficientes para sustentarem transferências de funções práticas e de divergências que incumbem a cada um uma predeterminação de responsabilidades e deveres. Estes que naturalizam sistemas de diferenças naturais. ${ }^{4} \mathrm{Em}$ tal esquema, as diferenças biológicas entre os sexos, masculino e feminino, podem ser levantadas como naturalização das justificativas sociais das diferenças sociais estabelecidas. Como na questão das diferenças anatômicas entre os sexos, que pode levar a uma divisão social no ramo do trabalho, em suas divisões objetivas e subjetivas, traduzidas na forma de funçóes e restriçóes às determinadas

\footnotetext{
$1 \quad$ Segundo a Organização Mundial da Saúde (OMS), violência é: "uso intencional da força física ou do poder, real ou em ameaça, contra si próprio, contra outra pessoa, ou contra um grupo ou uma comunidade, que resulte ou tenha grande possibilidade de resultar em lesôes, morte, dano psicológico, deficiência de desenvolvimento ou privação" (WHO, 2002, p. 5, apud TEIXEIRA; MENEGHEL, 2015, 371).

2 "Transcorridos cinco anos da vigência da Lei Maria da Penha, não houve avanço do Estado brasileiro, através do Poder Judiciário, no sentido de dotaro sistema judicial de condições de acesso à justiça para as mulheres vítimas de violência. Estudos comprovam a falta de destinação de recursos orçamentários para ampliação do número de Varas da Violência Doméstica e Familiar contra a Mulher; para ampliação do número de funcionários nas referidas varas e, por fim, para criação de serviços interdisciplinares integrados em rede, para efetivação das medidas urgentes de proteção, assistência e apoio aos agressores e vítimas, conforme estabelecido na Lei. Ou seja, de elementos que convencionamos identificar como Estrutura do Direito" (FEIX, 2011, p. 12).

3 Por exemplo como é visivelmente destacado os artigos $2^{\circ}$ e $3^{\circ}$ da respectiva lei que servem apenas acumulo textual, pois na pratica trazem pouca efetividade, onde destaca: "Art. 20 Toda mulher, independentemente de classe, raça, etnia, orientação sexual, renda, cultura, nível educacional, idade e religião, goza dos direitos fundamentais inerentes à pessoa humana, sendo-lhe asseguradas as oportunidades e facilidades para viver sem violência, preservar sua saúde física e mental e seu aperfeiçoamento moral, intelectual e social. Art. 3o Serão asseguradas às mulheres as condiçóes para o exercício efetivo dos direitos à vida, à segurança, à saúde, à alimentação, à educação, à cultura, à moradia, ao acesso à justiça, ao esporte, ao lazer, ao trabalho, à cidadania, à liberdade, à dignidade, ao respeito e à convivência familiar e comunitária. $\$ 1$ o O poder público desenvolverá políticas que visem garantir os direitos humanos das mulheres no âmbito das relaçôes domésticas e familiares no sentido de resguardá-las de toda forma de negligência, discriminação, exploraçáo, violência, crueldade e opressáo. \$2o Cabe à família, à sociedade e ao poder público criar as condiçôes necessárias para o efetivo exercício dos direitos enunciados no caput" (BRASIL, 2006).
}

BOURDIEU, 2002, 
profissões. Outro ponto que é nitidamente observado é a questão da dominação por meio da ideia até mesmo da representação das definiçôes sociais dos órgãos sexuais, como na representação dos órgãos femininos como opostos e diferentes, porém com a assunção de certas semelhanças; exemplo deste é a ideia da representação da Vagina como um órgão "invertido". A oposição entre os sexos também é destaque nas relações sexuais. Nelas a dominação e a inferioridade também são exaltadas ao atribuir ao órgão feminino o caráter funesto e maléfico, onde o homem em várias culturas deve "ficar por cima"; sendo às vezes até condenado pela "inversão do posto acima" pelas mulheres. ${ }^{5}$ Para justificar estes mecanismos de dominação, alguns povos recorrem à criação de mitos de origem, nos quais destacam as demais formas estabelecidas na ordem social. Como exemplo, tem-se a tradição da "cabila":

Foi na fonte (tala) que o primeiro homem encontrou a primeira mulher. Ela estava apanhando água quando o homem, arrogante, aproximou-se dela e pediu de beber. Mas ela havia chegado primeiro e ela também estava com sede. Descontente, o homem a empurrou. Ela deu um passo em falso e caiu por terra. Então o homem viu as coxas da mulher, que eram diferentes das suas. E ficou paralisado de espanto. A mulher, mais astuciosa, ensinou-lhe muitas coisas: 'Deitete, disse ela, e eu te direi para que servem teus órgão'. Ele se estendeu por terra. Ela acariciou seu pênis, que se tornou duas vezes maior, e deitou-se sobre ele. $\mathrm{O}$ homem experimentou um prazer enorme. Ele passou a seguir a mulher por toda parte, para voltar a fazer o mesmo, pois ela sabia mais coisas que ele, como acender o fogo etc. Um dia, o homem disse à mulher: 'Eu quero te mostrar que eu também sei fazer coisas. Estende=te, e eu me deitarei sobre ti'. A mulher se deitou por terra, e o homem se pôs sobre ela. E ele sentiu o mesmo prazer. E disse então a mulher: ' $\mathrm{Na}$ fonte, és tu (quem dominas"; na casa, sou eu'. No espirito do homem são sempre estes últimos propósitos que contam, e desde então os homens gostam sempre de montar sobre as mulheres. Foi assim que eles se tornaram os primeiros e são eles que devem governar. ${ }^{6}$

O mito apenas vai ao mesmo sentido de dominação que é comumente difundido, que é demonstrado no caso do ato sexual como uma relação de dominação. De modo geral, a dominação sexual masculina acaba sendo uma continuidade social masculina que se produz no sexo com a nomenclatura do possuir. As manifestaçóes da virilidade, por meio da posse sexual, nada mais são que a simples ratificação da dominação em mais um ramo. Tal ideia é tão forte, que a submissão sexual pela posse é vista como um ato de dominação;

\footnotetext{
$5 \quad$ BOURDIEU, 2002.

6 YACINE-TITOUH apud BOURDIEU, 2002, p.28.
} 
o que sofre a violência é feminizado, desonrado, o que acarretava, como no caso da sociedade grega, a perda de sua cidadania plena caso houvesse a feminizaçáo do homem; ou ainda, como na Roma antiga, onde o ato de passividade nas relaçóes homoafetivas do homem para com seus escravos era punido com a perda de seus títulos. ${ }^{7}$

A incorporação da dominação pela sociodiceia masculina se dá por duas formas: primeiro é dada uma legitimaçáo de natureza biológica do masculino sobre o feminino, em seguida, a naturalização da dominação por meio de uma construçáo social. ${ }^{8}$ Assim é dado por uma construçáo profunda dos corpos, impondo um diferencial do uso destes, fazendo-se acreditar na construçáo social de um masculino viril e da mulher a ser feminina por meio de um trabalho minucioso de construção social.

As divisóes constitutivas nas relaçóes sociais de dominação e de exploração classificam grande parte das coisas do mundo: uma divisão antagônica entre o masculino e o feminino. Dando às mulheres as tarefas supérfluas do cotidiano, ou consideradas pequenas, como cuidar das crianças ou realizar afazeres domésticos, como se fossem prazeres irrelevantes aos homens, que devem cuidar dos afazeres de honra como praticar o ato da caça, ou conseguir o sustento da casa para que a mulher cuide da manutençáo da economia domiciliar e afazeres domiciliares irrelevantes.

No que se refere às obrigaçóes, pode-se destacar a questão das obrigaçóes sociais criadas às mulheres como padróes estéticos, com a exclusão daquelas que não seguem determinada moda ou tendência atual, e físicos, a construção social de um padrão de perfeiçáo corporal a ser almejado pelas mulheres; obrigaçóes também no sentido familiar, em que a mulher é colocada como obrigada a atingir determinada idade na construção de um casamento e na criação de filhos; e caso não venha a atingir tal ideal fala-se que ela ficará para titia ou será uma encalhada. Quando as mulheres ainda decidem coincidir obrigaçóes laborais extrafamiliares, elas são postas em um paradoxo social a ser cumprido de forma homérica, no qual elas são postas em duas obrigaçôes, a familiar e a profissional, sendo que da mulher que se encontra nesta situação é requerida a perfeição em ambos os campos de atuação exercidos por ela; pois caso, por exemplo, ela venha a se dedicar ao trabalho e negligenciar a família, será considerada uma péssima mãe e esposa, já se valorizar demais a família será considerada uma má profissional ou uma mulher que quer depender exclusivamente do marido que não consegue ajudar a sustentar a casa. Sobre a questão de quando entram em determinadas profissóes elas não são consideradas como iguais por

DOVER, 1982 apud BOURDIEU 2002.

BOURDIEU, 2002. 
seus colegas. Como exemplo, pode ser visto o período entre as Duas Grandes Guerras do início do século XX, onde pela falta de mão de obra as mulheres assumiram os cargos de trabalho para substituir os homens. Todavia, com o fim da Segunda Guerra, os homens passaram a ser realocados em suas posiçôes anteriores. Com isso, para exercerem e manterse em determinados cargos as mulheres além de ter que preencher os mesmo requisitos curriculares que os homens, devem ainda ter capacidades adicionais, que são analisadas de diversos parâmetros de ponderação, como: a existência ou não de filhos, aspectos físicos e estéticos que se adequem aos padróes de belezas sociais, ser dotadas de uma capacidade extraordinária de superioridade para com seus pares no que diz respeito à execuçấo de suas tarefas. No que diz respeito às limitaçôes, tal ideia tem repercussão em vários ramos da sociedade. Por exemplo, quando uma mulher em sua capacidade laborativa tenta se inserir no mercado de trabalho, pode encontrar diversas resistências na área apenas pelo fato de ser mulher; como a ideia barbara de determinadas profissōes serem exclusivas para homens, e ainda, outras apenas para as mulheres quando exercem determinadas profissóes com a mesma cargo horaria e atribuiçóes aos homens ainda assim, recebem um salário inferior ao pago ao sexo oposto. Assim se concretiza o que se tem por violência simbólica. ${ }^{9}$ Violência simbólica pode ser conceituada, grosso modo, como uma forma de violência que cria limites e obrigaçóes às mulheres, na qual se encontram reunidas todas as condiçôes de seu exercício, tais são um conjunto de estruturas sociais e atividades de produção e reprodução que são fundamentadas na estruturação de uma divisão sexual do trabalho de reprodução e produção biológica e social, que exclui as mulheres, deixando aos homens os benefícios e ganhos. Para a violência simbólica ser eficiente, é necessário que os dominado incorporem as estruturas dominantes, fazendo de tal forma que tais estruturas sejam tidas como naturais; levando inclusive a uma autodepreciação ou autodesprezo. A dominação pela violência simbólica só é possível com cumplicidade do dominado e das estruturas utilizadas para a dominação que é incorporada pelo dominado de forma inconsciente. Assim, para Lopes:

A violência simbólica responde por submissões que não são sequer percebidas como tal se apoiam em expectativas coletivas, crenças socialmente inculcadas. A teoria da violência simbólica repousa sobre uma teoria da violência simbólica repousa sobre uma teoria de pro-

\footnotetext{
$9 \quad$ "Ao tomar "simbólico" em um de seus sentidos mais correntes, supôe-se, por vezes, que enfatizar a violência simbólica é minimizar o papel da violência física e (fazer) esquecer que há mulheres espancadas, violentadas, exploradas, ou, o que é ainda pior, tentar desculpar os homens por essa forma de violência. $\mathrm{O}$ que nấo é, obviamente, o caso. Ao se entender "simbólico" como o oposto de real, de efetivo, a suposiçáo é de que a violência simbólica seria uma violência meramente "espiritual" e, indiscutivelmente, sem efeitos reais. E esta distinçáo simplista, característica de um materialismo primário, que a teoria materialista da economia de bens simbólicos, em cuja elaboração eu venho há muitos anos trabalhando, visa a destruir, fazendo ver, na teoria, a objetividade da experiência subjetiva das relaçôes de dominaçáo" (BOURDIEU, P.2004, p. 46).
} 
dução da crença, segundo a qual é necessário um trabalho de socialização para produzir agentes dotados de esquemas de percepçáo e de apreciaçáo que lhes permitirão perceber as injunçóes inscritas em uma situação ou em um discurso e acatá-las. Esse poder se cumpre por e em uma relaçáo definida que cria a crença na legitimidade das palestras e nas pessoas que as pronunciam e se instaura na medida em que os que se submetem reconhecem os que as exercem. ${ }^{10}$

Se buscamos constatar, é grande o número de situaçóes concretas em que a violência simbólica é exercida. Como exemplo mais nítido dessa violência, tem-se o caso que em grande maioria as mulheres têm preferência por um companheiro mais velho e que seja mais alto que elas. Nesse ponto, nota-se a hierarquia sexual, pois aceitar o inverso é crer que a mulher dominante é rebaixada socialmente, por se sentirem representadas na imagem de seu parceiro; como se fosse necessária a exigência de o homem ocupar, pelo menos aparentemente, o espaço dominante da casa.

Portanto, somente com uma visão superficial por tais modelos, percebe-se a intensidade da violência exercida por estes, enraizados no íntimo da sociedade. Infelizmente, as violências contra a mulher vão muito além da violência simbólica. Ainda podem ser: auto-infligida em mulheres, contra mulheres idosas, de gênero, domestica, na gravidez, no namoro, nos serviços de saúde, obstétrica, patrimonial, psicológica, racial e sexual. A Lei Maria da Penha das formas de violência previamente destacadas, somente destaca em seu artigo $5^{\circ}$ a violência doméstica e no artigo $7^{\circ}$ a violência física, psicológica, sexual, patrimonial e moral, limitando de forma drástica o combate à violência contra a mulher. Mesmo que o rol especificado neste artigo contendo conceitos mais genéricos que podem abordar diversos tipos de violência, como a violência física ${ }^{11}$ e a moral; ${ }^{12}$ mesmo assim, não é suficiente para sanar tais crimes. A violência auto-infligida diz respeito a violência praticada contra si, como por exemplo ocorre no suicídio. As desigualdades de gênero são fatos presentes que levam à tais atos; principalmente, em mulheres com maiores condiçóes de risco como: casamentos precoce e arranjados, gravidez indesejada, abortos, dependência econômica do cônjuge, baixa escolaridade e condiçóes sociais. A prevenção é feita por meio da identificação de pessoas em risco e seu rápido encaminhamento a programas de prevenção ou centros psicossociais.

A violência contra mulheres idosas se dá principalmente pela negligência, violência

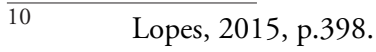

11 A violência física, entendida como qualquer conduta que ofenda sua integridade ou saúde corporal (BRASIL,2006).

12 A violência moral, entendida como qualquer conduta que configure calúnia, difamação ou injúria (BRASIL, 2006).
} 
psicológica, tratamento com preconceito, financeira e maus-tratos físico. Isso ocorre para a mulher idosa ser vista pela sociedade, além da questão do fato de ser mulher, por predisposiçóes simbólicas que as homogeneízam e estereotipam, levando ao descarte social. ${ }^{13}$ Tal violência é mais frequentemente praticada por membros da própria família.

A violência de gênero traz a questão das relaçóes de poder entre os sexos. O estudo sobre tal violência divide-se em três correntes teóricas; a da dominação masculina, que vem com um posicionamento de que é tanto vitima como cumplice da dominação do masculino sobre o feminino; a da dominação patriarcal, abordada de um viés marxista, onde a mulher como sujeito social autônomo é vitimada historicamente pelo controle patriarcal masculino; e a corrente relacional, que aborda o tema tratando a mulher como cumplice na dominação.

A violência doméstica, ${ }^{14}$ ou violência familiar como também é chamada, tem esse nome pelo fato de acontecer no interior da casa, e por isso, muitas vezes é a primeira violência com que se tem contato, normalmente ocorrendo de forma implícita. A dominação exercida no ambiente doméstico acaba sendo apenas uma reprodução da dominação masculina na sociedade. ${ }^{15}$ Segundo Rusche, ${ }^{16}$ a maior incidência de atos de violência contra a mulher se dá no ambiente do lar, normalmente ela exercida pelo marido, namorado ou companheiro. A violência na gravidez é uma violência física, psicológica, sexual, moral ou patrimonial exercida por parceiro durante o período da gestação. É gerada no próprio sistema de saúde, gerados por falta de cuidados durante o período gestacional por falta de treinamento dos profissionais de saúde. Violência no namoro é recorrente principalmente nas relações entre adolescentes, prejudicando o desenvolvimento e a saúde do(a) parceiro(a) e compromete sua integridade física, psicológica ou sexual. ${ }^{17}$ Os meios

BRITTO DA MOTTA, 2007, apud, TEIXEIRA, MENEGHEL, 2015.

14 Art. 5o Para os efeitos desta Lei, configura violência doméstica e familiar contra a mulher qualquer ação ou omissão baseada no gênero que lhe cause morte, lesão, sofrimento físico, sexual ou psicológico e dano moral ou patrimonial: I - no âmbito da unidade doméstica, compreendida como o espaço de convívio permanente de pessoas, com ou sem vínculo familiar, inclusive as esporadicamente agregadas; II - no âmbito da família, compreendida como a comunidade formada por indivíduos que são ou se consideram aparentados, unidos por laços naturais, por afinidade ou por vontade expressa; III - em qualquer relaçáo íntima de afeto, na qual o agressor conviva ou tenha convivido com a ofendida, independentemente de coabitação. Parágrafo único. As relaçóes pessoais enunciadas neste artigo independem de orientação sexual (BRASIL, 2006).

15 Vale lembrar, para melhor compreender o fenômeno da violência doméstica e intrafamiliar como violência de gênero, indissociável do conceito de violência política (ou seja, de instrumento para perpetuar relaçōes desiguais de poder), que o castigo físico ainda é prática culturalmente aceita e naturalizada como condição de afirmação da autoridade, ou poder familiar (antes conhecido como pátrio poder) dos pais sobre seus filhos (FEIX, 2011, p. 4).

16 Rusche, 2002, apud, TEIXEIRA; MENEGHEL.

17 NJAINE, 2015. 
de combate a ela têm três fases: a primeira, de prevenção, evitando a violência antes que ela ocorra; a segunda ocorre por uma resposta imediata durante a existência de tal violência, como assistência às vítimas; o terceiro nível ocorre à reabilitação das vítimas com a intenção de diminuir os abalos das violências.

Violência nos serviços de saúde acontece de várias formas, mas em especial na questão da saúde reprodutiva da mulher, também chamada de violência obstétrica. É tão intensa que mesmo com movimentos feministas de várias vertentes pressionando, o Programa de Assistência Integral à Saúde da Mulher (PAISM) admite a impessoalidade e negligência dos profissionais de saúde. ${ }^{18}$ Assim o sistema de saúde acaba sendo uma representação das hierarquias expostas na sociedade, negando um tratamento devido à mulher.

Violência Patrimonial se faz no caso onde a mulher ocupa um lugar de provedora no lar. A Lei Maria da penha traz tal definição:

Entendida como qualquer conduta que configure retenção, subtração, destruição parcial ou total de seus objetos, instrumentos de trabalho, documentos pessoais, bens, valores e direitos ou recursos econômicos, incluindo os destinados a satisfazer suas necessidades. ${ }^{19}$

Essa violência ocorre de forma mais nítidas em relação às pessoas idosas, pela sua situação de fragilidade, pois normalmente não é vista como violência por aqueles que a sofrem.

A violência psicológica, segundo a lei Maria da Penha, é:

II - a violência psicológica, entendida como qualquer conduta que lhe cause dano emocional e diminuição da autoestima ou que lhe prejudique e perturbe o pleno desenvolvimento ou que vise degradar ou controlar suas açóes, comportamentos, crenças e decisóes, mediante ameaça, constrangimento, humilhação, manipulação, isolamento, vigilância constante, perseguição contumaz, insulto, chantagem, ridicularizarão, exploração e limitação do direito de ir e vir ou qualquer outro meio que lhe cause prejuízo à saúde psicológica e à autodeterminação. ${ }^{20}$

Tal violência é de difícil detecção porque pode ser exercida de forma bem sutil sem mesmo que o violentado a perceba, ou somente a perceba quando é extrapolada a barreira da

\begin{tabular}{ll}
\hline 18 & DINIZ, 2015. \\
19 & Brasil, 2006. \\
20 & BRASIL, 2006
\end{tabular}


violência psicológica para a violência física. ${ }^{21}$

A violência racial é uma violência que no Brasil se incide especialmente sobre a população negra. Levando-se em conta a forma de abolição escravocrata que o Brasil realizou tardiamente em relação aos demais países, é possível apenas nesta observação se averiguar o alarmante conflito racial existente, e com isso, uma dupla discriminação contra a mulher negra. $\mathrm{O}$ conceito de violência racial é abrangido pelo conceito de violência já anteriormente destacado.

Violência sexual é uma das violências mais graves sofridas pela mulher. Tal conduta pode ser conceituada como:

Conduta que constranja a pessoa a presenciar, a mantar ou a participar de relaçáo sexual não desejada, mediante intimidação, ameaça, coação ou uso de força; que a induza a comercializar ou a utilizar, de qualquer modo, a sua sexualidade; que a impeça de usar qualquer método contraceptivo ou que a force ao matrimonio, à gravidez, ao aborto ou à prostituição, mediante coação, chantagem, suborno ou manipulação; ou que limite ou anule o exercício dos seus direitos sexuais e reprodutivos. ${ }^{22}$ Depois de ocorrida a violência a mulher deve ser submetida imediatamente a assistência medica para a administração dos devidos medicamentos que impeçam a transmissão de doenças ou uma possível gravidez, que caso ocorra, poderá ser realizada a prática do aborto, garantida por lei. ${ }^{23}$ Por todos os tipos de violência demonstrados, temos a violência contra a mulher como muito mais que um problema de violência, mas sim um problema social. Tal fato é bem evidenciado no ultimo Mapa da Violência sobre o homicídio de mulheres no Brasil (2012). O primeiro fato que se observa, é que ao se analisar o histórico de crescimento de homicídio de mulheres; no período antes da lei, de 1980 a 2006, o crescimento dos números de homicídio foi de 7,6\% ao ano, e o número de homicídios crescia 2,5\% ao ano; já após a lei, de 2006 até 2013, o crescimento do número de homicídioscaiu para $2,6 \%$ e a taxa cai para $1,7 \%$ ao ano.

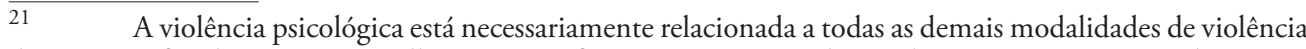
doméstica e familiar contra a mulher. Sua justificativa encontra-se alicerçada na negativa ou impedimento à mulher de exercer sua liberdade e condição de alteridade em relaçáo ao agressor. Ė a negaçáo de valor fundamental do Estado de Direito, o exercício da autonomia da vontade e, portanto,da condiçáo de sujeito de direitos conquistada pelos homens, nas revoluçôes burguesas, americana e francesa, já no século XVIII (FEIX, 2011, p. 5).

22

OLIVEIRA, 2015, p. 395.

23 A crença expressa no jargão "ajoelhou tem que rezar" implica uma comumnaturalização do uso da força e do constrangimento contra a manifestação e o exercício autônomo da vontade. Como se o "sim" dito no cartório, no altar, no bar ou no motel impusesse à mulher um consentimento permanente, inquestionável, infalível, irretratável. Não. O exercício da sexualidade deve ser sempre contratado, e os contratantes, para garantia de sua dignidade, devem ser livres para destratar a qualquer tempo (FEIX, 2011, p. 6). 
Nos níveis estaduais, as unidades federativas tiveram diminuições, entretanto, as taxas de crescimento mantiveram-se relativas a depender do estado. A partir da Lei Maria da Penha, apenas em cinco unidades federativas foi observada a queda das taxas: Rondônia, Espírito Santo, Pernambuco, São Paulo e Rio de Janeiro. Nos 22 estados restantes, no período de 2006 a 2013, as taxas cresceram com ritmos extremamente variados: de 3,1\% em Santa Catarina e indo até $131,3 \%$ em Roraima. ${ }^{24}$ Em questáo regional, a regiáo que mais se destaca no crescimento da taxa é a regiáo Nordeste, com um crescimento de $79,3 \%$ nos últimos 10 anos; seguida pela regiâo Norte com a taxa de 53,7\%. Dentro dos estados, têm-se dados opostos, enquanto que nas capitais os índices caíram 5,8\%, tendo Vitória, Maceió, João Pessoa e Fortaleza as maiores taxas no país no ano de 2013, sendo de mais de 10 homicídios por 100 mil mulheres; enquanto que as taxas estaduais cresceram em média de 8,8\%; assim, observando o problema da interiorizaçáo da violência. Nos municípios com mais de 10 mil habitantes do sexo feminino, ocorre um problema de constatação dos dados. No ano de 2013, em 637 (39,2 \%) municípios não foi registrado nenhum homicídio; em 122 (7,5\%) não houve quaisquer registros nos últimos 5 anos da pesquisa (2009 a 2013); não foi registrado em 2013 nenhum homicídio de mulheres em 4026 municípios do país (72,3\%). Assim percebe-se que o grande número de homicídios femininos em municípios de pequeno porte não é nem mesmo contabilizado. No ranking global, o Brasil ocupa uma posição preocupante. O país ocupa a $5^{\circ}$ posiçáo num grupo de 83 países, com sua taxa de 4,8 homicídios por 100 mil mulheres, excedendo média global. Como exemplo, em comparação com o Reino Unido, Dinamarca e Escócia, no Brasil ocorre $48,24 \%$ e 16 vezes mais homicídios femininos.

Quanto à cor das vítimas, na maioria dos casos, a população negra é vítima da violência. A partir da vigência da lei Maria da Penha, o número de vítimas entre mulheres brancas cai $2,1 \%$ e a das mulheres negras aumenta $35,0 \%$.

Em relação à idade das vítimas, é baixa ou quase nula até os 10 anos de idade, crescendo de forma íngreme até os 18 anos, a partir dessa idade, vai declinando até a velhice. Os meios mais utilizados para tais homicídios são: arma de fogo $(48,8 \%)$, cortante/penetrante $(25,3 \%)$, objeto contundente $(8,0 \%)$, estrangulamento $(6,1 \%)$ e outros $(11,8 \%)$. Para ambos os sexos, os maiores índices de homicídios são por arma de fogo, todavia no caso das mulheres tem-se uma maior participação dos demais meios, indicando maior presença de crimes de ódio ou por motivos fúteis. Por fim têm-se os locais onde ocorrem tais agressóes. Para as mulheres, os crimes são mais presentes nos ambientes mais "familiares" como em domicílio $(27,1 \%)$ e estabelecimento de saúde $(25,2 \%)$. Mesmo ocorrendo um

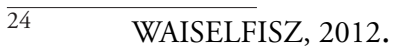


maior número ainda em vias públicas $(31,2 \%)$, percebe-se uma maior domesticidade dos homicídios das mulheres. Há ainda dados existentes no Sistema Único de Saúde (SUS), que faz o registro por meio do Sistema de Informação de Agravos de Notificação (SINAN), que traz dados mais específicos. Exemplos desses são dados como os dos agressores, que registram que $82 \%$ das agressōes a crianças do sexo feminino até 11 anos, $42,4 \%$ sofrem agressão pela mãe; para adolescentes de 12 a 17 anos, as agressões dividemse em 26,5\% pelos pais e 23,2\% pelos parceiros e ex-parceiros. Para as mulheres entre 18 a 59 anos, os principais agressores são os parceiros e ex-parceiros, correspondendo à metade dos casos; nas idosas, corresponde em grande parte pelos filhos $(34,9 \%)$. Os tipos de violência registrados são diversas, sendo a física a mais frequente, $48,7 \%$ dos atendimentos, seguindo pela violência psicológica, sendo 23,0\% dos atendimentos; na terceira posição com $11,9 \%$, está a violência sexual, tendo maior incidência em crianças e adolescentes. No caso de reincidência, acontece em praticamente metade dos casos registrados $(49,2 \%)$, especialmente nas mulheres adultas $(54,1 \%)$ e idosas $(60,4 \%)$.

Sobre os encaminhamentos, as principais instituições que os realizaram foram os conselhos tutelares, os Centros de Referência da assistência social (CREAS), as delegacias da criança e do adolescente, as delegacias da mulher, as varas da infância e da juventude; sendo $46,9 \%, 9,6 \%, 7,8 \%, 3,7 \%, 3,1 \%$; e $33,8 \%, 8,0 \%, 6,2 \%, 72$, \% e $2,5 \%$ respectivamente, para crianças e adolescentes.

\section{O CARIRI E A NECESSIDADE DE UMA CASA ABRIGO}

A própria Lei Maria da Penha exisge no artigo 35, parágrafo II: "casas-abrigos para mulheres e respectivos dependentes menores em situação de violência doméstica e familiar". Dessa forma, percebe-se a necessidade da criação de tal Casa no Cariri cearense.

Mas por que no Cariri? O Cariri, segundo o Ministério da Justiça (2015), é o local mais perigoso do Nordeste para mulheres, por ser localizado no sertão cearense, a cultura rural ainda se faz presente. ${ }^{25}$ Dessa forma, foi-se percebendo que, em meio a essa cultura machista rural, o Cariri cresceu, mas não perdeu essa cultura, ela se prolongou na questão

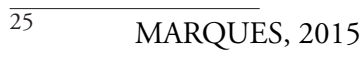


da violência doméstica e do feminicídio.

Com essa série de dados do Cariri, como caririense e mulher em uma aula de Teoria Feminista no curso de Direito, veio a ideia do Grupo de Pesquisa Gênero e Direito FAP (Na Faculdade Paraíso do Ceará), com 59 integrantes hoje, destes $80 \%$ composto de mulheres, as quais muitas pedem ajuda por sofrer problemas de violência, ou quando conhecem alguém que sofre algum tipo de violência. Com os dados analisados, iniciamos pesquisa de campo em Delegacia da Mulher de Juazeiro e Crato; Juizado Especial da Família e da Mulher; Centro de Referência; e com isso, os mais absurdos tipos de violência, desde a violência psicológica (Lei Maria da Penha, $\mathrm{n}^{\circ}$ 11. 340), que percebermos estar em todos os casos, pois antes de violência física sempre existiu a violência psicológica. Caso da adolescente surda-muda, que chegou ao Centro de Referência e que sofria violência (física e sexual) por 3 anos e não tinha como denunciar. Ou, um dos casos mais marcantes que foi o da mulher que chegou ensanguentada à Delegacia de Juazeiro do Norte, a qual o marido havia quebrado uma cadeira na sua cabeça, e ela antes de ir ao hospital sentia entalada na sua garganta a vontade de denunciar, ou dos casos de pedofilia em um dos bairros mais populares da cidade de Juazeiro, o Horto, onde se encontra a estátua do Padre Cícero, símbolo de fé dos católicos, e os casos de violência contra idosas no município de Barbalha que vez vêm crescendo, enfim da gama de violência patriarcal podemos perceber que o estudo árduo a esses locais nos ajuda a analisar essa construçáo identitária e machista no Cariri e no Brasil, pois o que acontece nessa Regiāo também é reflexo do que acontece no país. Podemos perceber pelos dados. Número de ocorrências registradas na Delegacia da Mulher de Juazeiro durante o período de janeiro a maio de 2015: Homicídio - 1; Tentativa de homicídio - 4; Lesão corporal leve - 90; Ameaça - 251; Estupro - 1; Estupro de vulnerável - 6; Sequestro e cárcere privado - 1; Injúria e difamação - 33 (Fonte: Delegacia da Mulher de Juazeiro do Norte, 2015). No primeiro semestre desse ano, segundo o Ministério de Políticas para Mulheres, mais de 350 mulheres foram mortas no Brasil em 2016. Dados do Instituto de Pesquisa Econômica Aplicada (IPEA) que divulgam mais de 15 mulheres são mortas por dia no país, e que quase 530 mulheres são estupradas.

Com o Grupo, também passamos a fazer extensão, o que leva a açóes no dia 25 de cada mês. Conhecido como o Dia Laranja, esse dia foi escolhido devido à campanha da ONU: Campanha UNA-SE Pelo Fim da Violência contra as Mulheres ${ }^{26}$ que prossegue:

Agências das Naçóes Unidas e organizaçóes da sociedade civil pro-

$\overline{26} \quad$ Mapa da Violência, 2015, p. 07. 
movem atividades para dar mais visibilidade às questóes que envolvem a prevenção e a eliminação da violência contra mulheres e meninas. A campanha é descrita como um movimento solidário que tem como foco a igualdade de gênero. ${ }^{27}$

Sendo assim, precisamos mostrar que é necessária uma casa de acolhimento para essa violência, no sentido de reafirmar a contínua pesquisa sobre gênero, ultrapassando essa categoria e chegando a geração, pois como foi dito acima, vimos meninas sofrendo pedofilia; e idosas sofrendo violência. Esse mesmo Mapa afirma que, quem mais bate nas filhas são as mães, e quem mais bate nas mulheres/mães idosas são as filhas (Mapa de Violência, 2015). Com essa informação, se pararmos para raciocinar, a questão da construção da identidade passa nesse sentido, pois esses tipos de violência estáo acontecendo com pessoas que estão em situação de fragilidade, sejam elas, meninas, mulheres, ou idosas, quando se está na forma frágil detém-se um poder pela violência, e é nesse sentido que construímos uma sociedade machista, pois as mães batem nos filhos, e no futuro os filhos (futuramente maridos) baterão em suas esposas. Sendo assim, esse ciclo sem fim só mostra que é preciso quebrar esse laço de violência com a cultura de paz. Portanto, quando iniciamos a questão da ação de extensão pensamos na possibilidade de falar de uma cultura de violência, e, sobretudo de pensar em uma cultura de paz.

Na medida em que se constrói conscientemente no indivíduo o sentimento de pertença ao gênero mulher, a pessoa adere mais às características de tal fragilidade feminina, o que não é algo imediato, mas sim um processo de aproximação do indivíduo com os elementos violência e submissão.

Sendo assim, podemos observar o quanto a cultura brasileira é impregnada com essa ideia. Portanto, é de suma importância discutir as questóes de gênero em todas as esferas na busca de uma igualdade de direitos fundamentais entre homens e mulheres. O movimento de mulheres, a universidade tem um papel importante na difusão de tal ideia, e na Região do Cariri são perceptíveis alguns fatos.

Mas quais são os mecanismos que as mulheres no Cariri podem usar para ter esse acesso à justiça? São eles: Conselho da Mulher; Centro de Referência; Delegacia da Mulher de Juazeiro do Norte; Juizado Especial da Família e da Mulher em Juazeiro do Norte, onde toda quarta e quinta são feitas as audiências. Em Crato há a Delegacia da Mulher e o Centro de Referência. Essas entidades de acesso à justiça não nasceram de forma tão simples, elas vieram com uma luta do movimento feminista desde 1993.

$27 \quad$ Idem. 
Um dos pontos cruciais à intervenção da questão da violência doméstica é a Casa Abrigo, uma entidade que já existiu em 2003 em Juazeiro do Norte, mas não abrigou nenhuma mulher, devido à perda de prazo pelo Governo do Estado. No entanto, com ajuda do Grupo de Pesquisa Gênero, Geração e Direito FAP, essa casa pode ser construída mais uma vez, com projetos doados da Faculdade Paraíso do Ceará.

\subsection{O que é casa abrigo}

Uma das respostas do Estado para fins de violência doméstica, que assegure a integridade física e moral das mulheres, é a casa abrigo. Nos termos da lei: “

Casa Abrigo é um serviço de caráter temporário, com o objetivo de oferecer moradia protegida, que funciona em local sigiloso e de atendimento integral a mulheres em risco iminente de morte em razão da violência familiar e doméstica. ${ }^{28}$ Uma das finalidades do referido mecanismo é provocar ruptura entre a situaçáo de violência e a mudança na qualidade de vida das mulheres. Dentre as atividades programáticas, no serviço de abrigamento, está o lazer, atividades educativas e de saúde. Tem duração de 90 a 180 dias.

A casa abrigo é oriunda de políticas públicas de abrigamento para mulheres em situação de violência doméstica. Para que funcione, é necessária uma atuação conjunta da Delegacia da Mulher (DM) e do Centro de Referência da Mulher (CRM) - uma unidade da Secretaria Especial da Mulher que tem a finalidade de oferecer atendimento psicológico, jurídico e social às vítimas. Quando a mulher está em situação de risco, a DM e o CRM acionam o Núcleo Estadual de Abrigamento para que esta seja inclusa no sistema de abrigamento, que tem por instrumento a Casa Abrigo.

O Brasil é comprometido internacionalmente a criar instrumentos para atender a mulher vítima e coibir a violência, pois assinou, em 1984, a Convenção sobre eliminação de todas as formas de discriminação contra a mulher, ratificada pela ONU em 1979. Além disso, conclui-se que a violência contra a mulher é um fenômeno mundial e antigo, visto que, na Inglaterra, na década de 70, já existiam 70 casas-abrigo, como forma de resolver o problema.

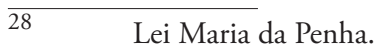


Uma linha de ação contra a violência são os serviços especializados, que são a casaabrigo, os centros de referência, centros de reabilitação e educação do agressor, juizados de violência doméstica e familiar contra a mulher e defensoria da mulher. Os serviços especializados devem ser fortalecidos para garantir a eficácia do enfrentamento e combate à violência.

A primeira casa-abrigo surgiu em São Paulo, no ano de 1986; hoje em dia, existem 72 casas-abrigo espalhadas em todo o território nacional, que se concentram em sua maior parte nas Regióes Sul e Sudeste. 37\% das unidades federativas possuem apenas uma casa abrigo. A maioria dos estabelecimentos encontra sua gestáo vinculada à assistência social e não ligada à questão de segurança pública, justiça ou saúde.

Em 2009, o serviço de abrigamento passou a ser denominado "serviço de acolhimento institucional para mulheres em situação de violência", isso quando foi enquadrado nos serviços sócio-assistenciais. Já as diretrizes, estão contidas nos termos de referência da Secretaria de Políticas para as Mulheres (SPM).

\subsection{Políticas Públicas e a questáo da instabilidade das Casas-Abrigo}

Políticas públicas podem ser entendidas como uma forma da administração pública tornar reais e materializar os direitos. Além disso, estudiosos afirmam que é uma forma de manobra política, um jogo de interesses, podendo mudar de governo para governo, daí afirmar-se que a Casa Abrigo é alvo de precariedades e fragilidades, pois pode fechar e reabrir a cada mudança de governo, vez que é uma política pública, ou seja, não goza de estabilidade. A mudança de um governo para o outro pode, inclusive, diminuir ou aumentar as desigualdades de gênero, pois depende dos interesses políticos do governo vigente.

A implementação de políticas públicas para as mulheres deve ser capaz de inserir os Direitos Humanos, principalmente no que diz respeito a uma vida livre de violência, além de tornar público e de cuidados do Estado o que antes era tratado como privado.

\subsection{Pacto Nacional de Enfrentamento à Violência Contra a Mulher}

Em 2005, o governo Lula criou a Política Nacional de Enfrentamento à Violência Contra as Mulheres, na qual é necessário fortalecer as mulheres para que possam romper 
com o ciclo da violência. Tal ciclo possui três fases: a primeira, marcada pelas tensôes no relacionamento, ocorrem agressóes verbais, crises de ciúmes, ameaças, destruição de objetos e etc.; na segunda fase, ocorre agravamento nas agressóes, sua característica principal são as agressôes físicas; na terceira fase, ou lua de mel, ocorre quando o agressor, por medo de perder a companheira, demonstra remorso e busca o perdão.

É por meio da Política Nacional que se garante às mulheres na situação de violência, assistência e direitos. É também o que estabelece os conceitos, princípios, o rumo que se deve tomar e as açóes que previnam a violência. No que tange ao conceito de enfrentamento, deve ser relacionada às políticas públicas, nas quais se faz necessária uma mobilização de todas as áreas do sistema, seja saúde, educação, segurança pública, justiça e etc.

Para dar mais agilidade a tal programa Federal, em 2007, o ex-presidente Lula lançou o Pacto Nacional pelo Enfrentamento à Violência Contra a Mulher, no qual foi feito um acordo entre os entes da Administração Direta; os 27 estados aderiram ao pacto. O estado de Pernambuco destaca-se por ter assumido o serviço de abrigamento, o qual abriu e deu estrutura a seis casas-abrigo espalhadas pelo estado. De 2009 a fevereiro de 2012, Pernambuco tinha um total de 417 mulheres e 630 crianças abrigadas.

A Política Nacional de Enfrentamento à Violência contra as Mulheres age desconstruindo as desigualdades e combatendo as discriminaçóes de gênero; interfere nos padróes sexistas; promove o empoderamento das mulheres e garante os direitos humanos das mulheres; assim como promove o acesso destas aos serviços especializados. A política nacional ainda amplia o conceito de violência contra as mulheres, englobando violência doméstica e familiar, o assédio sexual, a violência institucional, entre outros.

Além disso, incluiu quatro dimensôes para o enfrentamento à violência contra a mulher, que são: a prevenção, o combate, a assistência e a garantia de direitos. Além disso, houve a necessidade de estabelecer-se vínculo com a Política Nacional de Enfrentamento ao Tráfico de Pessoas, a Política Nacional de Assistência Social, Política Nacional de Saúde das Mulheres, entre outras. A SPM priorizou um maior e melhor atendimento às mulheres em situaçáo de violência, foi assim que surgiram os CRM's, as defensorias da mulher, promotorias da mulher, juizados especializados de violência doméstica e familiar, e Central de atendimento à Mulher. 
A ação governamental vai desde o incentivo a serviços especializados e a rede de funcionamento e atendimento do sistema, capacitação de agentes para o atendimento, até uma maior acessibilidade da mulher à justiça, assim como para questóes de segurança.

\subsection{A Política do Abrigamento}

Para conceituar abrigamento, é necessário expandir o conhecimento e visar a Política Nacional de Enfrentamento à Violência Contra as Mulheres, portanto, abrigamento são as diversas formas de acolhimento provisório. Tais formas materializam-se emserviços, programas e até benefícios, tudo destinado a mulheres vítimas de violência. Devemos incluir em tal conceito, não somente o acolhimento em si, mas também tudo aquilo que contribua para o bem-estar físico, psicológico e social das vítimas. Lembrando que ao ocorrer o acolhimento das vítimas, faz-se necessário um acompanhamento por um serviço especializado de atendimento e uma articulação com a segurança pública.

Existem algumas recomendaçóes feitas ao sistema de acolhimento, que têm por base o que trata a Política Nacional de Enfrentamento à Violência Contra as Mulheres, algumas são : garantir o cumprimento de tratados e acordos internacionais ratificados pelo Brasil; confirmar a existência da violência de gênero, etnia e raça como decorrente de um contexto histórico e estrutural; as políticas de abrigamento devem funcionar junto às áreas da saúde, educação, assistência, habitação, trabalho, direitos humanos e justiça; capacitação de profissionais para assistência às mulheres vítimas; e articulação do sistema de abrigamento, principalmente, com a segurança pública para fornecer segurança físicopsicológica-social.

\subsection{Diretrizes norteadoras do processo de abrigamento}

As Diretrizes Nacionais de Abrigamento às Mulheres em situação de Violência servem para nortear, guiar todo o processo de acolhimento de mulheres vítimas de violência assim como dar parâmetros ao fluxo de atendimento nas redes de serviços. Procura abranger as diversas formas de violência contra a mulher e promove novas formas de abrigamento. 
As Diretrizes Nacionais de Abrigamento têm por base os princípios propostos no Plano Nacional de Políticas para as Mulheres, que são a Igualdade e Respeito à Diversidade, Autonomia das Mulheres, Laicidade Estatal, Universalidade das Políticas, Justiça Social e o princípio da Participação e Controle Social.

Adentrando um pouco aos princípios: Igualdade e Respeito à Diversidade tratade garantir que todos tenham direitos iguais, homem ou mulher, verificando o respeito a diversidade cultural, racial, inserção social, situação econômica e regional, entre outros; no princípio da Autonomia das Mulheres, estas têm o direito de decisão e influências, seja sobre suas vidas, seus corpos, na comunidade ou no país.

$\mathrm{Na}$ Laicidade do Estado, as políticas públicas para as mulheres devem ser feitas independentemente dos princípios religiosos; na Universalidade das Políticas, as políticas públicas devem garantir às mulheres o acesso às diversas áreas e setores sociais; na Justiça Social, deve ser assegurada a redistribuição dos recursos e riquezas e uma superação da desigualdade social; e o Princípio da Participação e Controle Social, dá o direito à participação e debate de políticas públicas.

\section{COMO FUNCIONA A CASA-ABRIGO}

Para um perfeito funcionamento das Casas-Abrigo é necessário haver: vinculação à assistência social, para proporcionar garantia de estabilidade; institucionalização, pois as casas-abrigo deverão ser criadas por lei e ter parcerias com órgãos gestores, garantindo maior segurança tanto para as mulheres como para as profissionais atuantes; atuação junto à segurança pública, para a garantia de proteção dos direitos da mulher e seus respectivos filhos abrigados; outro fator importante é manter o sigilo, capaz de garantir a segurança das vítimas;e por fim, deve haver um acompanhamento após o abrigamento, que deverá ser feito pelo CRM mais próximo ou pelo Centro Especializado de Referência de Assistência Social (CREAS), promovendo à mulher acesso à habitação e trabalho

O sistema de abrigamento tem ocorrido de diferentes formas nos estados e municípios brasileiros, visto que não existe uma uniformidade na rede de atendimento para o encaminhamento ao programa. Para tanto, as Diretrizes Nacionais trazem uma forma padronizada, uniforme, para o atendimento. 
As etapas para o abrigamento iniciam-se com os serviços demandantes, especializados ou não (Delegacias da Mulher, Defensorias da Mulher, CRM e etc,), que identificarão o caso de acolhimento; em seguida, a mulher será encaminhada para o CRM mais próximo, na falta deste, será encaminhada para o CREAS, ambos terão a função de avaliar o caso por meio de uma entrevista (horário comercial); e ainda o próprio serviço da Casa-Abrigo pode, em plantão, fazer a averiguação do caso (horário extra-comecial); em um terceiro momento, identificada a necessidade do serviço de acolhimento, o CRM, o CREAS, ou o próprio serviço da Casa Abrigo terá que realizar a locomoção da mulher e seu(s) filho(s), se assim os tiver. No caso de local sigiloso, o transporte ocorrerá por conta de motorista próprio da Casa Abrigo e nos casos de maior perigo à vítima, a locomoção será feita por uma autoridade policial.

Por último, após o término do serviço, o CRM ou o CREAS deverá prestar um acompanhamento à vítima para que seja garantida a sua reintegração à vida social. Será no momento da avaliação pelo CRM, CREAS, ou pelo serviço de abrigamento, que ocorrerá a individualização do caso e assim a inclusão da mulher ao serviço correto de ajuda, seja uma casa de acolhimento provisório, a casa abrigo ou outro meio alternativo ao acolhimento. Nos locais que não possuam um CRM ou um CREAS, deverá ser informado ao serviço sócio-assistencal, para que este faça o devido encaminhamento ao local mais próximo de acolhimento às mulheres vítimas de violência.

\section{DIFICULDADES ENFRENTADAS PELA CASA ABRIGO}

As profissionais atuantes da CRM afirmam haver inúmeras dificuldades e desafios que cercam o sistema de abrigamento, o principal deles é a recusa da mulher ao ingressar em tal mecanismo, isso porque ela terá que optar, se assim desejar, pelo abandono de tudo e de todos do seu convívio, desde o trabalho ao convívio familiar. Para tanto, alguns estudos levaram a conclusão da necessidade de se contribuir também para uma melhor compreensão, por parte das mulheres, da situação e das dificuldades de ingresso e permanência no instrumento.

O serviço de abrigamento, embora preserve a vida, muitas vítimas acabam recusando a inclusão no mecanismo, ou até abandonando, porque, além de ter que abrir mão dos laços afetivos e vínculos sociais, as mulheres abrigadas não podem receber visitas, não 
podem ter celular, entre outros. Muitas delas desistem porque se sentem em uma prisão, porém, muitas outras entram no programa por não ter escolha.

O sigilo também traz dificuldades ao funcionamento da casa abrigo devido as suas exigências, tais como a mudança constante de endereços; a não possibilidade de um imóvel próprio e a necessidade de se alugar imóveis, que não apresentarão as condiçôes necessárias à manutenção da casa abrigo. Além disso, pode ocorrer a quebra do sigilo devido a fatores como o município ser pequeno, ou por parte de ex-residentes, ou até devido o agressor ter tomado conhecimento do endereço, entre outros. Portanto, para haver uma proteçâo maior ao sigilo é importante que se tenham estratégias que incluam: a guarda de policiais femininas ou guarda municipal feminina, institucionalização das casas abrigo, formalização de parcerias, maior articulação com a comunidade, maior tecnologia, entre outros.

Além da pouca popularidade da casa abrigo, estudos apontam que as mulheres inclusas no programa de abrigamento possuem, em sua maioria, baixa escolaridade, o que dificulta a qualificação profissional e autonomia econômica, fatores que aumentam a vulnerabilidade da mulher e dificultam a saída do ciclo de violência. Portanto, devemos entender a casa abrigo como uma última medida a ser tomada. Para tanto, os profissionais da Política Nacional de Enfrentamento a Violência devem criar meios para fortalecer a cidadania da mulher, assim como sua segurança, extinguindo qualquer sentimento de injustiça ou aprisionamento, principalmente no que tange a Casa Abrigo.

\section{COORDENADORIAS DA MULHER}

Vinculado ao ministério da justiça, em 1985 foi criado o Conselho Nacional dos Direitos da Mulher. Os conselhos de direitos são facultativos a nível estadual e municipal e vêm demonstrando insuficiência na luta pelo combate à violência contra a mulher. Tal insuficiência levou à criação das secretarias e coordenadorias de mulheres, que possuem poder de execução, maior articulação e melhores condiçóes de intervenção pública.

A Coordenadoria da Mulher é gênero, enquanto a Casa Abrigo é espécie, ou seja, aquela é responsável por criar soluçóes que ajudem a mulher vítima a sair do seu ciclo de violência; um dos meios pensados são as Casas-Abrigo e as Casas de Passagem (ou Casas de Acolhimento Provisório). Portanto, as coordenadorias possuem uma maior articulação do que as Casas de Acolhimento. 
As secretarias e coordenadorias têm a missão de contribuir para a promoção da igualdade de gênero, através de meios como a formulação, coordenação e articulação de políticas para as mulheres. Além disso, visam aeficácia dos programas e açóes governamentais; organizar indicadores; promover parcerias público-privadas e com movimentos sociais; e visam articular-se com as demais secretarias e órgãos governamentais em busca de seus objetivos.

As coordenadorias realizam atividades como orientação por telefone às mulheres que precisam agendar atendimento; prestação de serviço-referência para acompanhamento em caso de violência e devidas providencias; encaminhamento para serviços de saúde em casos de violência sexual e doméstica. Têm significativa contribuição para o fortalecimento de açôes para a redução da vulnerabilidade das mulheres excluídas, assim como garantia de direitos sexuais e reprodutivos (planejamento familiar, pré-natal e etc.).

\section{PROGRAMAS DE ENFRENTAMENTO À VIOLÊNCIA}

Os programas de enfrentamento da violência configuram-se em açóes e estratégias de prevenção, proteção e intervenção. Tais ações e estratégias são planejadas e articuladas a nível federal, estadual e municipal, sendo executadas pelas secretarias municipais da sua rede local, com a finalidade de reduzir atos violentos e nortear açóes de cuidado às vítimas. Priorizam, acima de tudo, maior investimento na prevenção, quando se observa a pretensão de reduzir a violência e seus agravos, pois é prevenindo que se combate tanto a violência como os gastos com as sequelas provenientes desta.

Tais programas criam açóes especificas para cada grupo populacional (crianças, idosos, mulheres, e etc.) respeitando e articulando-se de acordo com a necessidade de cada grupo. Apesar da especificidade, apresentam alguns pontos em comum, como a atenção integral às pessoas vítimas de violência; formulação de ações de prevenção e promoção de saúde para a parcela populacional mais vulnerável; a notificação da ocorrência da violência para que haja a produção de dados (informação); assim como a capacitação e educação contínua dos profissionais responsáveis pela sua área de atuação dentro do programa (principalmente relacionada à saúde). 


\section{CONSIDERAÇÓES FINAIS}

É crucial falar e trazer o Projeto Casa Abrigo para o Cariri é preciso que os pontos de apoio como a Delegacia e Defensoria para a mulher busquem a fomentação desse Projeto que já está pronto e qualificado para ser executado, encontrando-se em anexo os projetos: Arquitetônicos e o Plano de Ação, os quais foram entregues ao Conselho Municipal da Mulher de Juazeiro do Norte.

Ao longo do texto foi averiguado o quanto ainda precisa ser feito, estudado e analisado para diminuir essa cultura da violência e implantar-se uma cultura de paz.

Portanto, aqui ficam registrados os procedimentos jurídicos cabíveis para a implementação da Casa-Abrigo no Cariri, como também a execução deste, de tal forma pelo apelo que sentimos ao ver no rosto das mulheres agredidas o clamor por segurança e justiça.

\section{REFERÊNCIAS}

BOURDIEU, P. A dominaçáo masculina. 11º ed. Rio de Janeiro: Bertrand Brasil, 2012.

BRASIL. LEI No 11.340, de 7 de agosto de 2006. Lei Maria da Penha. Disponível em: $<$ http://www.planalto.gov.br/ccivil_03/_Ato2004-2006/2006/Lei/L11340.htm>. Acesso em: 16 de dezembro de 2017.

BRASIL. Lei 2.848 de 07 de dezembro de 1940. Dispóe sobre o Código Penal Brasileiro

Cantadas na rua são consideradas assédio sexual. Disponível em: <http://www.brasil.gov. br/cidadania-e-justica/2016/11/cantadas-na-rua-sao-consideradas-assedio-sexual.

DIAS, F. N. O medo enquanto emoçáo social: Contributos para uma sociologia das emoçôes. Forum Sociológico, no 15/16 (II Série), 2006.

GERHARDT, T. E.; SILVEIRA, D. T. Métodos de Pesquisa. Porto Alegre: Editora da Ufrgs, 2009. p. 18. 
GEERTZ, C. A interpretaçáo das culturas / Clifford Geertz. - l.ed., IS.reimpr. - Rio de Janeiro:LTC, 2008.

GIL, A. C. Métodos e Técnicas de Pesquisa Social. 6. ed. São Paulo: Atlas, 2008. p. 12 e 51 .

FEIX, V. Das formas de violência contra a mulher - artigo $7^{\circ}$. 2011. Disponível em: <http://www.compromissoeatitude.org.br/wp-content/uploads/2014/02/2_artigo-7. pdf $>$. Acesso em: 16 de dezembro de 2017.

TEIXEIRA, E. F.-; MENEGHEL, S. N. Dicionário Feminino da Infâmia: acolhimento e diagnóstico de mulheres em situação de violência. Rio de Janeiro: editora FIOCRUZ, 2015 .

WAISELFISZ, J.J. Mapa da Violência 2012. Os novos padrōes da violência homicida no Brasil. Caderno Complementar 1: Homicídio de mulheres no Brasil. São Paulo. Instituto Sangari. 2012. 